\title{
Characterizing the Potential Predictability of Seasonal, Station-Based Heavy Precipitation Accumulations and Extreme Dry Spell Durations*
}

\author{
BRUCE T. ANDERSON \\ Department of Earth and Environment, and The Frederick S. Pardee Center for the Study of the Longer-Range Future, \\ Boston University, Boston, Massachusetts \\ DAN GiANOTTI AND GUIDO SALVUCCI \\ Department of Earth and Environment, Boston University, Boston, Massachusetts
}

(Manuscript received 4 June 2014, in final form 23 December 2014)

\begin{abstract}
The release of seasonal (and longer) predictions of various climatological quantities is now routine. While undoubtedly devastating to lives and livelihoods, it is unclear whether seasonal extremes in precipitation-for example, extreme dry spells leading to droughts or heavy precipitation events leading to flooding-represent a feasible target for these predictions, that is, whether they are potentially predictable or are instead inherently unpredictable more than a few days to weeks in advance. This paper assesses the potential for predicting seasonal extremes in observed precipitation as a function of region and time of year by decomposing the station-based variance into that attributable to short-memory behavior of typical meteorological events-as generated from station-specific, seasonally varying, daily time-scale stationary stochastic weather models (SSWMs) - and that attributable to longer-time-scale, potentially predictable changes in precipitation-producing processes. Findings suggest the potential for making skillful predictions of seasonal precipitation extremes over the United States is enhanced (reduced) during the cool (warm) season, particularly for heavy precipitation event accumulations. Further, this potential is accentuated along the West Coast, around the Great Lakes, and over the central plains and Ohio River valley but is diminished over the Northeast and northern Great Plains. However, findings also suggest the potential for producing seasonal (and longer) predictions of seasonal precipitation extremes is spatially and seasonally dependent. As such, this paper includes supplemental material for the potentially predictable variance of seasonal extreme dry spell lengths, heavy event accumulations, and total accumulations at 774 stations across all 365 days so readers can evaluate the potential predictability for the location, timing, and metric of most relevance to them.
\end{abstract}

\section{Introduction}

Variations in precipitation, particularly those associated with extreme deficits or surpluses, have substantial economic, social, and environmental impacts (e.g., Riebsame et al. 1990; Kogan 1995; Easterling et al. 2000; Phillips 2002). While these variations in precipitation can occur on

\footnotetext{
* Supplemental information related to this paper is available at the Journals Online website: http://dx.doi.org/10.1175/JHM-D-14-0111.s1.

Corresponding author address: Bruce Anderson, Department of Earth and Environment, Boston University, 685 Commonwealth Ave., Rm. 130, Boston, MA 02215.

E-mail: brucea@bu.edu
}

seasonal, interannual, and decadal time scales, often it is unclear whether (and how) systematic, climate-induced shifts in the underlying characteristics (e.g., frequency and intensity) of daily precipitation events contributed to these variations. Indeed, much of this variability may arise simply from the stochastic evolution of daily precipitation events during a finite time period, which, while potentially detrimental, are inherently unpredictable more than a few days to weeks in advance (e.g., the 2012 central Great Plains drought; Kumar et al. 2013).

As such, in analyzing the predictability (or lack thereof) of seasonal to multidecadal variations in precipitation, it is useful first to assess the amount of variability that is potentially predictable (PP; e.g., Leith 1978; Madden and Shea 1978). Doing so allows one to isolate the regions, seasons, and time scales for which 
there are the most potential for success in making climate forecasts, either using short-term seasonal forecasting systems or long-term climate simulation systems. Further, the isolation of "hot spots" (and cold spots) of potential predictability can subsequently guide future analyses that improve our process understanding of the role that regional- and large-scale atmospheric circulations and ocean and land surface forcings play in inducing predictable changes to regional precipitation extremes on seasonal to decadal time scales.

One traditional way to estimate the PP signal is to perform "perfect" model simulations utilizing multiple runs of a numerical, coupled ocean-atmosphere model, albeit one in which the ocean is either allowed to evolve freely or is fixed to follow the evolution of the observed ocean itself (e.g., Rowell 1998; Boer 2000; Collins 2002; Moron et al. 2006; Boer and Lambert 2008; Schubert et al. 2008; Becker et al. 2013). Simulations of one run (the observed state) can then be compared with those from the others (the forecasted states) to determine the signal-to-noise ratio for various regions and to estimate the potential for predicting variations in precipitation for these regions. However, the model-based estimates of PP may by biased if the underlying numerical models are unrepresentative of the observed system, particularly with regard to their representation of weather and climate extremes, which tend to be singular, infrequent occurrences with sometimes limited spatial range (Tebaldi et al. 2006; Fowler and Ekström 2009; Kumar et al. 2014); further, they may be limited by the number of models that are incorporated and the number of runs that can be performed (Kiktev et al. 2007; Pryor et al. 2009; Fowler and Wilby 2010).

As a complement to these studies, others have used the observed data themselves to estimate the PP signal found within the full range of variability. For instance, one can estimate the stochastically generated variability by calculating the power spectra for a daily meteorological time series during a given season (across all years) and its associated variance, which in turn provides an estimate of the year-to-year variance of the seasonal-mean values (Madden 1976; Madden and Shea 1978). However, this method requires a (approximately) continuously varying, normally distributed daily time series, which is appropriate for sea level pressure (Madden 1976) and temperature (Madden and Shea 1978), but not necessarily for daily precipitation (e.g., Zheng et al. 2000). Alternatively, some of these limitations can be overcome through various bootstrapping techniques (e.g., Feng et al. 2011). However, such techniques necessarily incorporate both stochastically generated variability and variability in response to external drivers (Stocker et al. 2010) into both significance testing (Alexander et al. 2006; Kiktev et al. 2007; Pryor et al. 2009) and thresholds for extremes (e.g., Zhang et al. 2004).
To get around these issues, we have followed the lead of others (e.g., Singh and Kripalani 1986; Shea and Madden 1990; Gregory et al. 1993; Katz and Parlange 1998; Wang et al. 2006, 2007) and adopted a methodology that utilizes stationary stochastic weather models (SSWMs) - that is, models in which the simulated interannual-to-decadal precipitation variance is purely the result of the random evolution of daily precipitation events within the given time period-to better constrain the range of variability that may arise simply from the stochastic, short-memory behavior of typical meteorological events over time. Given this range of variability, it is then possible to identify the observed precipitation variations that lie outside the envelope of variability produced by chance, allowing us to quantify the PP variability that is likely to have arisen from systematic changes in the underlying precipitation characteristics not captured by the stationary statistical characteristics found in the SSWM.

Using these SSWMs, we have previously quantified the PP variance (PPV) in seasonal-mean precipitation characteristics for 774 weather stations across the continental United States (Gianotti et al. 2013, 2014). For this study, our explicit focus is on the potential predictability of station-based seasonal precipitation extremes. While it is recognized that historically most climate forecasts have necessarily been derived from gridded climate model output, which in general cannot be compared directly with station observations (Chen and Knutson 2008), interpolating observed data to discrete grid boxes would necessarily reduce the spatial and temporal variations (Hamlet and Lettenmaier 2005) that generate the extremes that a given location actually experiences. Further, the growing use of statistical downscaling techniques to translate coarse-scale model dynamic and thermodynamic fields into station-specific predictions/projections (Robertson et al. 2009; Verbist et al. 2010; Wu et al. 2012; Doblas-Reyes et al. 2013) makes such a station-based analysis highly relevant for future operational efforts.

Section 2 presents an overview of the data and statistical methods employed to quantify the potential predictability of climate-induced variations in precipitation extremes across the United States. The temporal and spatial characteristics of potentially predictable extremes are then presented in section 3. Section 4 summarizes the results and discusses their implications for understanding the role climatic factors-such as atmospheric teleconnections, preceding land surface conditions, and/or anthropogenically driven trends-versus short-memory, stochastic behavior-such as that generated by immediate meteorological causes-play in generating these seasonal extremes. 


\section{Data and methods}

\section{a. Data}

As in previous work (Gianotti et al. 2013, 2014; Pal et al. 2013), we use the serially complete daily precipitation data compiled by the U.S. Historical Climatology Network (USHCN) spanning from 1 January 1900 through 31 December 2009 (Williams et al. 2006), which are based on a subset of the quality-controlled (Reek et al. 1992) National Climatic Data Center (NCDC) Summary of the Day data selected so as to minimize changes in instrumentation and recording times. From the 1218 available USHCN weather stations, 774 are selected that have at least 80 years of data with less than $5 \%$ missing values. All data end in 2009, with the earliest beginning in 1900. As such, all stations have data records that are from 80 to 110 years in length, starting in 1930 and earlier.

While most results will be presented at the station locations themselves, for secondary fields we also present interpolated values. For the interpolation, we use the Australian National University Spline (ANUSPLIN) software package (Hutchinson 1995, 2007), which is a thin-plate smoothing spline program often used to spatially interpolate hydrometeorological variables. To fit the spline, we use a bivariate, second-order spline (with longitude and latitude as independent spline variables) and minimize the generalized cross-validation error to determine the optimal smoothing parameter. For this study, only the time of year is presented as an interpolated value. To properly represent values across the transition from the end of the calendar year to the beginning, we perform the interpolation separately using the real and imaginary components of the annual cycle (represented by Julian days); these are then recombined to arrive at the interpolated angle and converted into the appropriate (interpolated) Julian day value.

\section{b. Calculation of extremes}

For consistency, many studies analyze extremes based on standard climate indices produced by a working group tasked with identifying these indices [the Expert Team on Climate Change Detection and Indices (ETCCDI); Peterson et al. 2001]. It is recognized that alternate, mathematically derived indices may provide more accurate (and informative) estimates of the extremeness of daily precipitation event distributions (e.g., Zolina et al. 2009, 2013) than can be obtained from the simple, observation-based ETCCDI metrics. However, given that this study is one of the first to begin to assess the predictability of extreme events (not necessarily the extremeness of their distributions), we felt it best to base these initial predictability estimates on "conventional" ETCCDI metrics with which the community is familiar (e.g., Klein Tank et al. 2009), albeit with slight modifications described below.
Generally speaking, extremes can result either from an absence of precipitation or an excess of precipitation. Of the 11 ETCCDI precipitation indices, 10 are designed to capture excess-precipitation extremes, with only one [the maximum consecutive dry day count (CDD)] designed to capture extremes associated with the absence of precipitation. As such, in order to investigate the potential to predict extreme droughts during a particular time of year, we will analyze the longest consecutive period of no precipitation within each 91-day season, equivalent to ETCCDI's CDD index (Peterson et al. 2001; May 2004; Alexander et al. 2006). Following the lead of Groisman and Knight (2008), for this study we consider any daily accumulation of less than $1 \mathrm{~mm}^{-1 a y}{ }^{-1}$ to constitute a "no precipitation" day. Doing so allows us to exclude days of very light precipitation that may otherwise truncate long dry spell runs; in addition, it accounts for the gradual transition of stations to more sensitive instrumentation during the early part of the record (e.g., Groisman et al. 2012).

To investigate the potential predictability of intense storm activity during a particular time period, we could feasibly use a metric such as the amount of total precipitation during a given time period (in our case seasonal 91-day periods) generated by daily rainfall events exceeding the $95 \%$ threshold (found from the cumulative distribution function of all nonzero daily rainfall amounts within the given 91-day window across the entire observational record), equivalent to the official ETCCDI R95pTOT index (Klein Tank et al. 2009); we note here that there are alternate definitions in the literature for "R95pTOT" as either an actual accumulation (e.g., Klein Tank et al. 2009) or a fractional accumulation relative to the total precipitation during the given time period (e.g., Alexander et al. 2006; Zolina et al. 2009). To alleviate any confusion, we will follow the lead of Zhang et al. (2011) and refer to the total accumulation generated by such events as "R95p."

At the same time, as noted, this metric only considers the most extreme precipitation events, which increases the likelihood that in many years no precipitating events will exceed the given threshold, resulting in a highly nonnormal distribution (Leander et al. 2014). To alleviate this issue, Leander et al. (2014) proposed an alternate index in which the threshold for extremes is recomputed each year/ season, ensuring that a finite number of events contribute to the cumulative sum each period, which they termed S95pTOT. However, while such an index is applicable on annual time scales, for seasonal time scales (comprising approximately 90 days), it may not be feasible to obtain an observed (i.e., nontheoretical) $p>0.95$ threshold value for each season. So, in order to capture a finite set of heavy (albeit not extreme) precipitation events, here we calculate the amount of total precipitation during a given time period generated by daily rainfall 
events within the upper quantile $(20 \%)$, which we term "S80p" analogous to the "R95p" terminology used by Zhang et al. (2011). Even then, some stations (particularly during the dry season) do not experience enough overall precipitation events to obtain an observed $p>0.80$ threshold value. In that case, the single largest event is used to represent the cumulative precipitation from heavy events during the given 91-day season. It is important to note that by construction this metric represents the accumulation associated with heavy-to-extreme precipitation events relative to those experienced at the given station for the given time of year, not that associated with events exceeding a constant (i.e., absolute) precipitation event amount (e.g., $20 \mathrm{~mm}$ day $^{-1}$ ).

\section{c. Calculation of potential predictability}

To determine the potential predictability of seasonal precipitation extremes across the United States, we first simulate the inherently unpredictable variability associated with stochastic, short-memory processes using statistically based chain-dependent daily rainfall models, which account for the occurrence and intensity of daily rainfall events (Katz 1977; Swift and Schreuder 1981; Wilks 1999). For reference, a schematic diagram detailing the following methodological steps can be found in supplemental Fig. S1 of Gianotti et al. (2014). First, to properly represent the high-frequency variability in daily precipitation occurrence, we use Markov chain models with seasonally varying transition probabilities and chain orders (Gianotti et al. 2013). Specifically, for each day of the year parameters are fit to the empirical data for chain orders from 0 to 5 days, and the appropriate model for each day is selected using the corrected Akaike information criterion (AICc; Hurvich and Tsai 1989) to optimize the goodness-of-fit/ parsimony trade-off. To further improve the robustness of transition probability estimates, at each station we pool data across a day-specific time window (e.g., in Ajo, Arizona, a window of 17 days surrounding Julian day 169 from every year is used for estimating the transition probabilities for Julian day 169 itself). The length of this station- and time-specific window is also selected using the AICc. Details of this procedure are provided in Gianotti et al. (2014).

To represent high-frequency variability in daily precipitation intensity, we use continuous parametric density functions. To allow for bimodal precipitation distributions with always-finite variances, the intensity models take the form of a five-parameter gammagamma probability distribution mixture model (which itself is selected from among a number of 1-5 parameter models by AICc). As with the occurrence process, for each station a separate model is constructed for each combination of day of year, pooling size, and chain order (conditioning on the previous $m$ days' occurrence, rather than intensity), with both the data pooling size and chain order selected using AICc. Using each station's variable-order, seasonally varying but annually stationary stochastic daily rainfall model, we then create 1000 stochastically generated Monte Carlo simulations of the 80-110-yr historical record for the given station.

Using the observed and stochastically generated data, we define [following Boer (2004) and Rowell (1998)] the potential predictability as the fraction of the observed variance that can only be ascribed to climatic (low frequency) variability:

$$
\mathrm{PP}(\operatorname{var}, d)=\frac{\sigma_{\mathrm{obs}}^{2}-\overline{\sigma_{\mathrm{sim}}^{2}}}{\sigma_{\mathrm{obs}}^{2}},
$$

where PP represents the potential predictability estimate (or equivalently the PPV), var is the variable of interest, $d$ is the day of year, $\sigma_{\text {obs }}^{2}$ is the observed year-toyear variance in the given variable across the $+80-\mathrm{yr}$ station record, $\sigma_{\text {sim }}^{2}$ is the stochastically simulated yearto-year variance in the given variable across an identical time window, and the overbar represents the median of the 1000 stochastically simulated variance estimates. To account for missing observational data at a particular station during a particular day, we simulate missing days using the SSWM for that location and day. This is more conservative than either inputting missing values with resampled observations or omitting the data entirely [the SSWMs have no persistence beyond 5 days, and thus, any precipitation sequences (longer than 5 days) that incorporate SSWM data are underdispersed relative to the actual conditions and will therefore tend to moderately underestimate the PP signal]. For each day of the year, we select a seasonal 91-day window centered on that day. Using that seasonal 91-day window, we can calculate the observed variable for each year, the stochastically simulated variable for each year, and through Eq. (1) the potential predictability of the variable on that day of the year.

To determine the statistical significance of these observed PP estimates, we estimate the probability distribution of the PP statistic under the null condition defined by no potential predictability. This is accomplished by applying Eq. (1) with the observed record variance (i.e., $\sigma_{\text {obs }}^{2}$ ) substituted with each of the 1000 stochastically simulated variances:

$$
\mathrm{PP}_{\text {sim }}(\operatorname{var}, d, n)=\frac{\sigma_{\text {sim }}^{2}(n)-\overline{\sigma_{\text {sim }}^{2}}}{\sigma_{\text {sim }}^{2}(n)},
$$

where $n$ designates a member of the ensemble from 1 to 1000. Again, we calculate the values for seasonal 91-day windows centered on each day of the year. Using the 


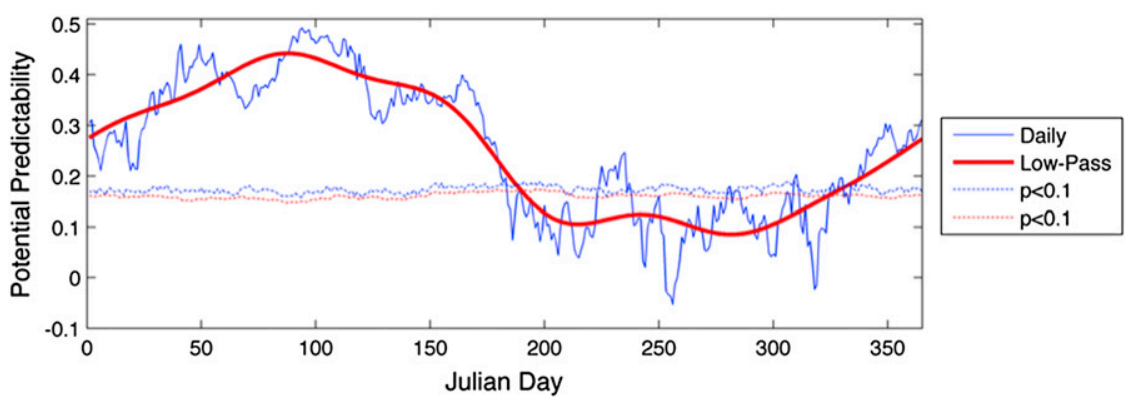

FIG. 1. Annual cycle of the PP of S80p within 91-day windows centered on a given Julian day at Princeton, Indiana. Blue lines represent daily PP values (solid) and the $p<0.10$ values for the same day, based on a one-tailed test utilizing the cumulative distribution of PP values returned by the 1000 stochastically generated 90 -yr records for that day (dashed). Red lines represent the low-pass-filtered PP values with a wavenumber 5 cutoff (solid) and the $p<0.10$ values for the same day, based on a similar low-pass filtering of the 1000 stochastically generated $90-\mathrm{yr}$ records (dashed).

cumulative distribution of these $1000 \mathrm{PP}$ values (for a given day) - which, by construction, are purely the result of short-memory stochastic variations-we can determine the probability that the observed PP estimates for that day are generated from similar stochastic variations. Here we choose a directional $p<0.10$ threshold, that is, we only consider observed PP estimates to be significantly different from zero if they lie above the 90th percentile of the stochastically generated distribution.

To remove artificial peaks (and troughs) of predictability (which on a day-to-day basis tends to be a noisy field; Fig. 1), the seasonal cycle of potential predictability of both the observed [Eq. (1)] and stochastically simulated [Eq. (2)] data is low-pass filtered using a Fourier transform truncated at wavenumber 5 (equivalent to a 73-day period). This results in 365 seasonally varying estimates of potentially predictable variance for each variable at all 774 stations and will serve as the basis for the rest of the analysis.

\section{Results}

\section{a. Potential predictability of heavy precipitation accumulations}

First, we investigate the potential to predict heavy-tointense storm accumulations during a particular time period. Considering first the traditional calendar seasons (winter, December-February; spring, March-May; summer, June-August; fall, September-November), we find that, with the exception of summer, every season shows coherent regions of PPV. Potential predictability is greatest in winter (Fig. 2a), with the largest values found over much of the western United States. In addition, heavy precipitation amounts contain PPV extending from the Great Lakes down the Ohio River basin and into the lower Mississippi River basin, as well as along the southern Atlantic plains states (the Atlantic plains include parts of New Jersey, Delaware, Maryland, Virginia, North Carolina, South Carolina, Georgia, Florida, and Alabama). Moving into spring (Fig. 2b), PPV continues to be found along the West Coast, extending into the interior Northwest and Southwest. In addition, coherent PP values are also found over the northern central plains (the central plains include Illinois, Wisconsin, Minnesota, Iowa, and Missouri along with eastern North and South Dakota, Nebraska, and Kansas). The PP values in this region persist into summer (Fig. 2c); additional summer PPV is also found over the Atlantic plains states. Generally, however, it is weak over most regions during this time. In fall (Fig. 2d), PPV continues to be found over the northern central plains and the Atlantic plains; in addition, it is also enhanced over the Northwest, which has PP values equivalent to those found in winter, suggesting that wintertime processes influencing the PP of heavy precipitation events in this region (and others) may impact this region earlier than most.

While the above analysis examines the potential predictability of heavy precipitation events (and their accumulation) for specific fixed times (i.e., the traditional seasons), it is also possible to investigate the potential predictability for other seasonal (i.e., 91 day) windows. For example, we can isolate the timing of the wet and dry season at a given station, based on the climatological maximum and minimum values of the S80p accumulations (Fig. 3), which is similar but not identical to the seasons with maximum and minimum total precipitation accumulations (not shown). Over the West Coast, the wet (dry) season occurs from early to late winter (from late summer to early fall). By contrast, over the southwest monsoon region (representing the northward extent of the North American monsoon), the wet (dry) 


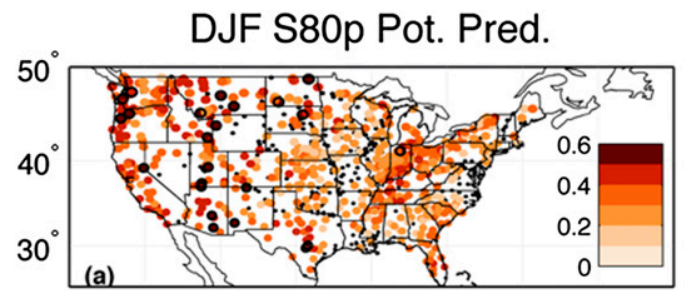

JJA S80p Pot. Pred.

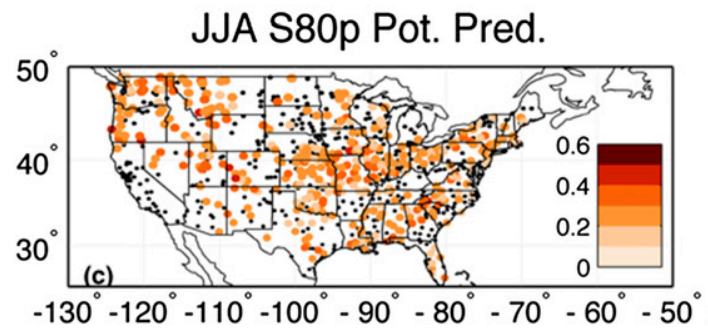

FIG. 2. Fraction of variance of a station's S80p within (a) winter, (b) spring, (c) summer, and (d) fall that is PP. For these calculations, the heavy precipitation event threshold is adjusted for each season/year based on the number and intensity of events that occurred within that fixed period (see text for details). PPV is determined by the difference between $\sigma_{\mathrm{obs}}^{2}$ and $\sigma_{\text {sim }}^{2}$ at that station, normalized by $\sigma_{\mathrm{obs}}^{2}$ [see Eq. (1)]. Only values with $p<0.10$ are shown, based on a one-tailed comparison with the cumulative distribution of PP values returned by the 1000 stochastically generated +80 -yr records for that station and season. Values (unitless) range from 0 to 0.6 and are given by the color bar on the rhs. Black outlines indicate stations in which over $50 \%$ of the observed variance is PP. Stations with insignificant PP are shown as a black dot.

season is found in late summer (late spring). Across the Great Plains, central plains, and Great Lakes, the wet (dry) season occurs in late spring and summer (midwinter). To the south, over the lower Mississippi River basin, the timing of the wet (dry) season shifts to the spring (fall). Along the southeastern coast, the wet (dry) season occurs in summer and early spring (early winter), while to the north it occurs in fall (late winter). The magnitudes of the accumulations associated with heavy precipitation events during these times (not shown) is highest over the Northwest and Southeast coastal locations, with minimum accumulations across the interior west and a general gradient toward higher values over the eastern portion of the United States. The region with the highest (lowest) seasonality tends to be the coastal Northwest (interior Southeast) locations.

Overall, the PP of heavy precipitation amounts is greater during the wet season compared with the dry season. Indeed, up to $50 \%$ of the variance in heavy accumulation amounts during the wet season is potentially predictable for many stations along the West Coast. Wet season PPV is also high over the interior west and the
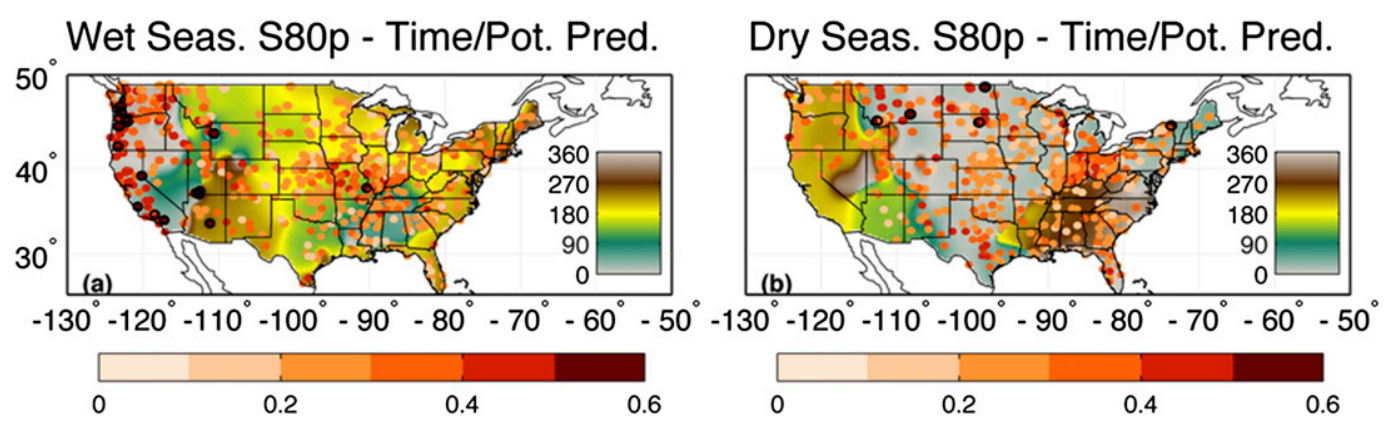

FIG. 3. Timing and PP of S80p during the wet and dry seasons at each station. (a) Shading shows the timing of max climatological S80p within a 91-day window, representing the Julian day at the center of the wet season. Values (Julian day) range from 0 to 365 and are given by the color bar on the rhs with green, yellow, brown, and gray representing 1 Apr, 1 Jul, 1 Oct, and 1 Jan, respectively. Circles represent the fraction of PPV of a station's S80p within the 91-day window centered on the day of max climatological S80p values. Values (unitless) range from 0 to 0.6 and are given by the color bar at the bottom. Black outlines indicate stations in which over $50 \%$ of the observed variance is PP. Stations with insignificant PP are not shown. (b) As in (a), but for the timing and PP during the dry season at each station, represented by the Julian day of the min climatological S80p value. 


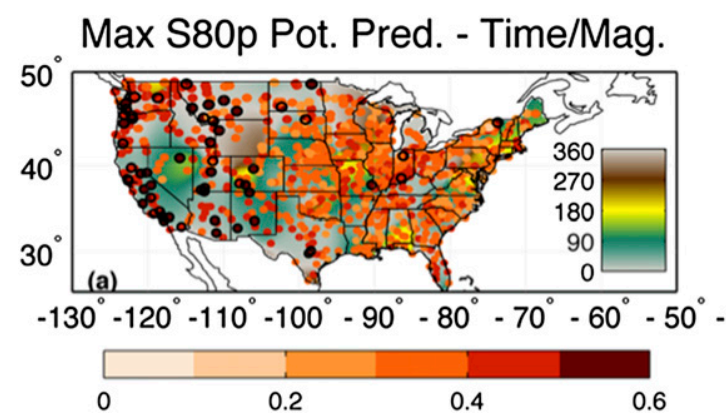

Min S80p Pot. Pred. - Time/Mag.

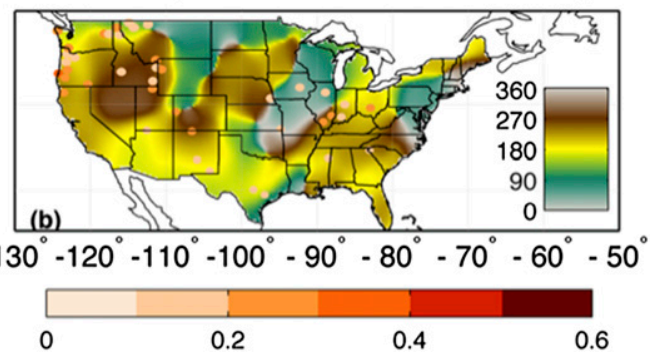

FIG. 4. Timing and PP of S80p during seasons with greatest and least PP at each station. (a) Shading shows the timing of max PP of S80p within a 91-day window, representing the Julian day at the center of that window. Values (Julian day) range from 0 to 365 and are given by the color bar on the rhs with green, yellow, brown, and gray representing 1 Apr, 1 Jul, 1 Oct, and 1 Jan, respectively. Circles represent the fraction of PPV of a station's S80p within the 91-day window centered on the day of max S80p PP. Values (unitless) range from 0 to 0.6 and are given by the color bar at the bottom. Black outlines indicate stations in which over $50 \%$ of the observed variance is PP. Stations with insignificant PP are not shown. (b) As in (a), but for the timing and PP on day of min S80p PP at each station.

central plains states. By contrast, the PPV of heavy accumulation amounts during the wet season is relatively low over the Atlantic plains and the Great Plains. During the dry season, most of the PPV is found along the northern portion of the United States, extending from the interior Northwest across the northern Great Plains and central plains and over the Great Lakes states (all of which experience their dry season at approximately the same time, namely, from the middle to end of winter). There is also a less coherent band of PPV extending from the interior Northwest down into Texas (from early to late winter dry seasons) and over the coastal Southeast (late fall dry season). By contrast, the PPV of heavy accumulation amounts during the dry season is relatively low across much of the West Coast and northeastern regions.

An alternate way to define our seasons of interest is by identifying the given 91-day window with the highest and lowest potential for predicting heavy precipitation accumulations. Although the timing of highest and lowest PPV (Fig. 4) shows less spatial coherence than the timing of the climatological maximum and minimum heavy precipitation accumulations themselves, there are nevertheless some broadscale features of interest. Along the West Coast of the United States, PP values tend to be highest (lowest) in early spring (summer) in the southern regions, while in the northern regions they are highest (lowest) from early to midwinter (from spring to summer). The winter (from spring to summer) maximum (minimum) in PPV extends across much of the northernmost states. Over the interior western United States, the timing of highest PPV is less well defined; however, the minimum tends to occur during fall in the interior Northwest and during summer in the interior Southwest. Over the central plains, timing of highest (lowest) PPV is centered around spring and early summer (fall and early winter), while to the south of the Great Lakes and over the Ohio River basin, the highest (lowest) PPV tends to occur during winter and early spring (late summer and fall). Along the southern portions of the Eastern Seaboard, the timing of highest (lowest) PPV occurs from late winter to early spring (late summer and early fall), while over the northern portion the timings are less coherent but generally reversed, such that highest (lowest) PPV occurs from late summer to fall (early spring).

With regard to magnitude, during the season with the lowest potentially predictable variations (Fig. 4b), the PP itself is insignificant at all but a few stations. As such, the timing of the least predictable seasons (described above) is of more interest than the magnitudes themselves. During the season with highest potentially predictable variations (Fig. 4a), the PP values are large (and significant) at all but a few stations. These tend to be largest $(>0.50)$ over much of the western United States (from early to late winter). Over the Great Plains and the Eastern Seaboard, the values decrease somewhat. However, PPV is again relatively large around the Great Lakes and over the Ohio River basin (from winter to early spring).

\section{b. Potential predictability of extreme dry spells}

Again, starting with the traditional calendar seasons, we find that, generally speaking, the potential to predict extreme dry spells is less than for heavy precipitation amounts (cf. Figs. 2, 5). PP values tend to be highest during fall and winter over the northern central plains and around the Great Lakes (Figs. 5a,d). During winter, there is also PPV in the length of extreme dry spells over the interior western United States, extending from the 
DJF CDD Pot. Pred.

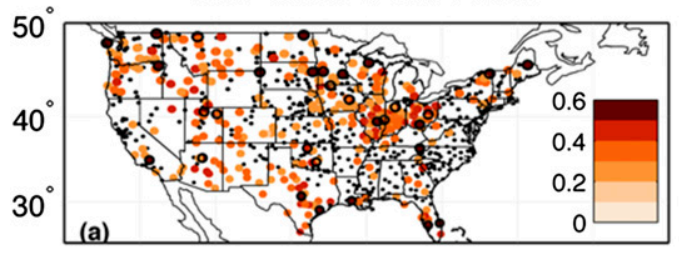

JJA CDD Pot. Pred.

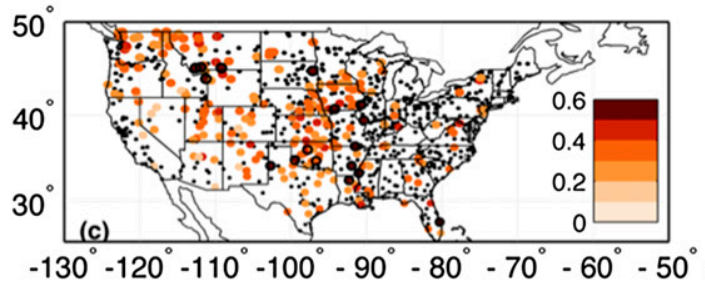

MAM CDD Pot. Pred.

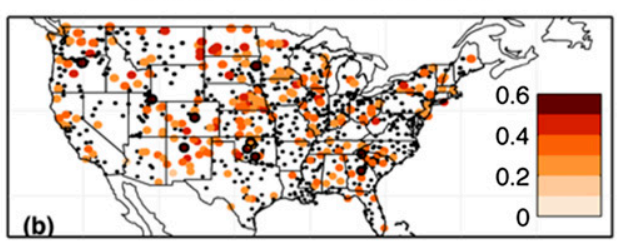

SON CDD Pot. Pred.

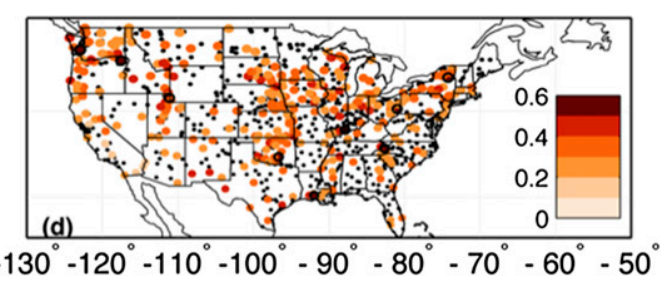

FIG. 5. As in Fig. 2, but for the fraction of variance of a station's longest CDD length within a given calendar season that is PP.

Canadian Rockies down into Texas. Interestingly, over the coastal Northwest, potential predictability of the occurrence (and length) of extreme dry spells is higher during fall than winter. In spring, coherent PP of extreme dry spells is found over the Great Plains, as well as across Colorado and New Mexico. Moving into summer-the period with weakest PP of heavy precipitation amounts- there appears to be enhanced PP of extreme dry spell lengths, particularly over the interior Northwest and central plains.

Turning to the climatological wet and dry seasonsdefined here relative to the climatological maximum (dry) and minimum (wet) CDD lengths (Fig. 6) -we find similar, but slightly varying, timings as compared with the S80p wet/dry seasons. Again, along the West Coast the wet (dry) season occurs from early to late winter (late summer and early fall), while over the southwest monsoon region the wet (dry) season is found in late summer (late spring), and across the Great Plains and central plains the wet (dry season) occurs in late spring and summer (midwinter). The greatest difference in timing is found around the Great Lakes and across the Ohio River basin, where the timing of the wet (dry) season occurs predominantly in spring (fall), as opposed to summer (winter). This timing mimics that found farther to the south over the interior Southeast, while along the southeastern coast, the wet (dry) season again occurs in summer and early spring (early winter). The magnitude of the extreme dry spell durations during these times (not shown) is lowest over the northeastern quadrant of the United States (during both seasons) and highest over the southwestern quadrant (again during both seasons), with the highest (lowest) seasonality found over the coastal Southwest (Northeast) locations.

Overall, the potential predictability of extreme dry spell durations during the wet season is limited, both in magnitude and spatial coherence (Fig. 6a). While particular stations have substantial PPV $(>0.5)$, most have insignificant PP values and those that do have relatively little spatial coherence. By contrast, during the dry season

Wet Seas. CDD - Time/Pot. Pred.

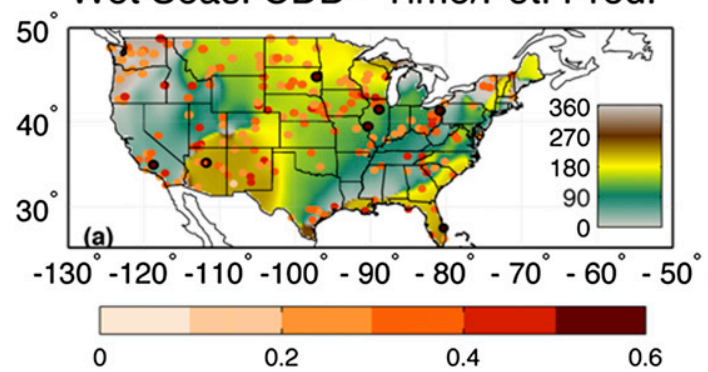

\section{Dry Seas. CDD - Time/Pot. Pred.}

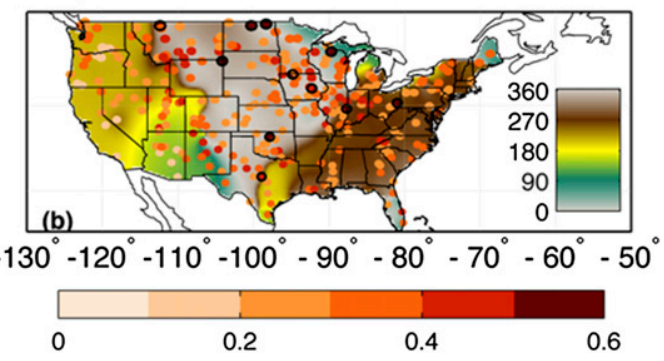

FIG. 6. As in Fig. 3, but for timing and PP fraction of variance of a station's longest CDD length during the (a) wet and (b) dry season at each station, as represented by the timing of min and max climatological CDD values within a 91-day window, respectively. 


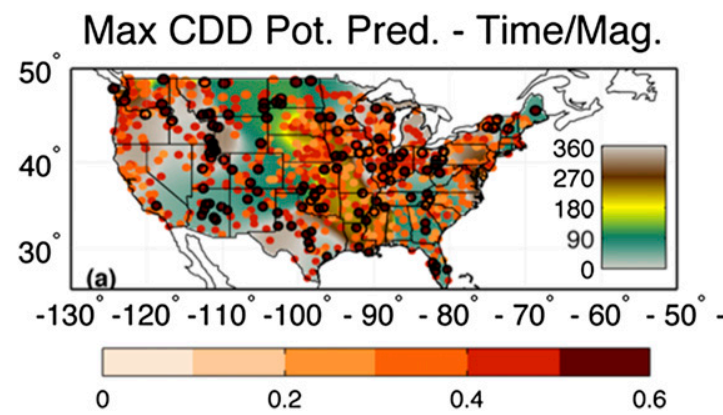

\section{Min CDD Pot. Pred. - Time/Mag.}

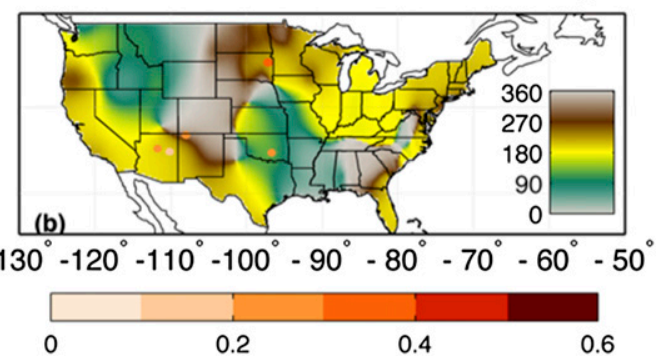

FIG. 7. As in Fig. 4, but for timing and PP fraction of variance of a station's longest CDD length during the 91-day window centered on the day of max and min CDD PP, respectively.

(Fig. 6b), PPV of extreme dry spell lengths appear more coherent, particularly over the northern central plains and Great Lakes. In addition, dry season variance extending from the Canadian Rockies down into Texas is potentially predictable (albeit at different times of the year, ranging from winter-spring over Texas through to summer-fall over the interior Northwest).

The fact that the PPV during the wet and dry seasons is similar to that found during the traditional seasons (and in some cases is substantially lower) suggests that PPV may be greater during the "shoulder" seasons between the wet and dry seasons. As such, we now examine the PP values and timings for the seasons with the highest and lowest PPV (Fig. 7). Not surprisingly, the amount of PPV in extreme dry spell lengths is uniformly high during the seasons with maximum PP values; further, substantially more stations contain very high PPV $(>0.5)$ as compared with heavy precipitation accumulation PPV (cf. Fig. 4a). The regions of very high PPV tend to be located over the interior western United States, as well as over the central plains, the Mississippi and Ohio River basins, and the southern Atlantic plains (Fig. 7a). Also of interest is the timing of maximum PPV. Over the Southwest and extending into the high plains, extreme dry spell PPV is highest during late winter and into spring. Over the Northwest, PP shifts to earlier in the season (late fall and early winter). Moving inland, over much of the Great Plains extreme dry spell length PPV is highest during summer and into early fall (although the northern portions tend to have highest PP values earlier in spring). Around the Great Lakes, though, PPV is greatest during winter, while along the Eastern Seaboard, PP values tend to be a maximum during spring and fall (over the southern and northern portions, respectively).

When considering the timing of least PPV (Fig. 7b), it is not surprising to find that most stations show no significant PP values; hence, the metric of most interest is the timing when PPV tends to reach a nadir. Starting again from the western United States, we find PPV is lowest from summer into fall, although in the northernmost portions PP values of extreme dry spells are lowest during spring. This spring minimum extends from the Northwest across the Canadian Rockies. Over the northern Great Plains extending southward to the Rocky Mountain plateau, PPV minima tend to be found from late fall to winter. To the east, PPV minima shift to summer and early fall around the Great Lakes, the Ohio River valley, and the Northeast (as well as the southern Atlantic plains). To the south, PPV minima over the Mississippi River basin and interior Southeast tend to occur during late winter and early spring.

\section{Conclusions and discussion}

In this paper, we sought to quantify the potential predictability of observed precipitation extremes over the United States on seasonal to multidecadal time scales. To do so, we constructed stationary stochastic weather models (SSWMs) based on observed stationbased daily precipitation characteristics, which can be used to establish the envelope of variability in seasonal extremes that arises solely from the stochastic, shortmemory behavior of typical meteorological events over time. We then calculated the fraction of observed variability in seasonal precipitation extremes across the United States that lies outside this envelope produced by chance. We refer to this fraction of the observed variability as the potentially predictable variance (PPV) because it is unlikely to have arisen simply from the stochastic (i.e., random) evolution of daily precipitation events constrained by fixed daily precipitation characteristics (Singh and Kripalani 1986). By extension, it is the spatiotemporal structure of this unexplained variance that can be used to isolate regions and seasons that are influenced by potentially predictable changes in the underlying precipitation-producing processes.

Based on this analysis, we found the following:

- Summed over the year, the PPV of heavy precipitation accumulations tends to be greater than the PPV of extreme dry spell lengths (Fig. 8), particularly along 
Cumulative S80p Pot. Pred.

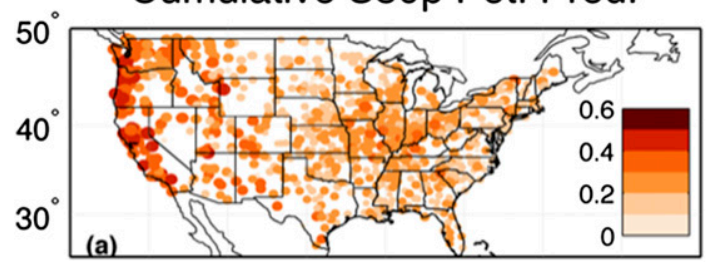

Cumulative CDD Pot. Pred.

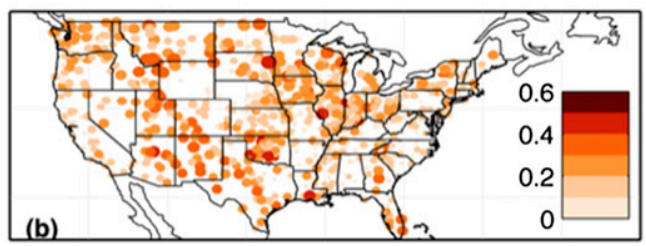

FIG. 8. (a) Cumulative fraction of variance of a station's S80p that is PP. For these calculations, $\sigma_{\text {obs }}^{2}$ and $\sigma_{\text {sim }}^{2}$ for each 91-day season centered on each Julian day is summed across the year. The difference between the two sums is then normalized by the sum of the observed variances across the year. Values (unitless) range from 0 to 0.6 and are given by the color bar on the rhs and the size of the circles. (b) As in (a), but for the cumulative fraction of variance of a station's longest CDD length.

the West Coast and the central plains. In these regions, heavy precipitation accumulation PPV occurs primarily from boreal winter to spring (cf. Figs. 2a,b), although relatively high values over the Northwest are also found during boreal fall.

- Further, during most seasons the PPV of heavy precipitation accumulations is greater and more geographically extensive than the PPV of extreme dry spell lengths. The exception is during boreal summer, when extreme-dry-spell-length PPV tends to be relatively larger, particularly over the central plains and Northwest.

- For both heavy precipitation accumulations and extreme dry spell lengths, PPV during the climatological wet and dry seasons (as determined by the timing of the maximum and minimum climatological values of the respective metric) tend to be equivalent to, or less than, PPV found during the traditional calendar season. This is particularly true for extreme dry spell lengths, but also for heavy precipitation accumulation. These results suggest that highest PPV of both metrics is found during the transition or "shoulder" seasons between the climatological wet and dry seasons.

- The timing of maximum PPV for heavy precipitation accumulations is found predominantly during boreal winter (Fig. 9a) extending into boreal spring. Relatively few stations have their maximum PPV occurring in boreal summer. Further, the magnitude of the maximum PPV values for heavy precipitation accumulations also tend to increase in boreal winter. These high PPV values tend to be found across much of the western United States, as well as over the Ohio River valley (cf. Fig. 4a).

- Complementary to this finding, the timing of minimum PPV for heavy precipitation accumulations is found predominantly during boreal summer extending into boreal fall (Fig. 9c). These summertime minima are found across much of the western United States and the Great Plains, as well as the Ohio River valley and the southern Atlantic plains (cf. Fig. 4b). Interestingly, however, a relatively large fraction of stations also experience a minimum in PPV during late boreal winter and spring (Fig. 9c), particularly over the northern tier of the United States, the central plains, and the Northeastern Seaboard (cf. Fig. 4b).

- In contrast to heavy precipitation accumulations, the timing of maximum PPV for extreme dry spell lengths is more evenly distributed across the year, although there is still a tendency for stations to experience their highest PPV during boreal fall and boreal winter (Fig. 9b). These stations tend to be located across the central plains and Great Plains and in the vicinity of the Great Lakes (cf. Fig. 7a). In addition, a relatively large fraction of stations also experience a maximum in PPV during late boreal spring, particularly over the interior Southwest and the southern Atlantic plains.

- The timing of minimum PPV for extreme dry spell lengths is found predominantly during boreal summer (Fig. 9d), particularly over the West Coast and Southwest, the Great Lakes and Ohio River valley, and the Northeast (cf. Fig. 7b). In addition, a relatively large fraction of stations also experience minimum PPV during boreal spring (predominantly the Northwest and southern Great Plains) and early boreal winter (predominantly the northern Great Plains), even as a relatively large fraction of stations are experiencing their maximum PPV (cf. Figs. 9b,d).

Overall, these results suggest that the potential for predicting year-to-year (or longer) changes in seasonal precipitation extremes is spatially and temporally dependent. In addition, as results show here, it is also metric dependent. Within this paper, we have only presented results for two "conventional" metrics of seasonal precipitation extremes. However, there are other measures of extremes that may better represent the full distribution of seasonal precipitation and dry spell duration (e.g., Zolina et al. 2009, 2013), as well as 

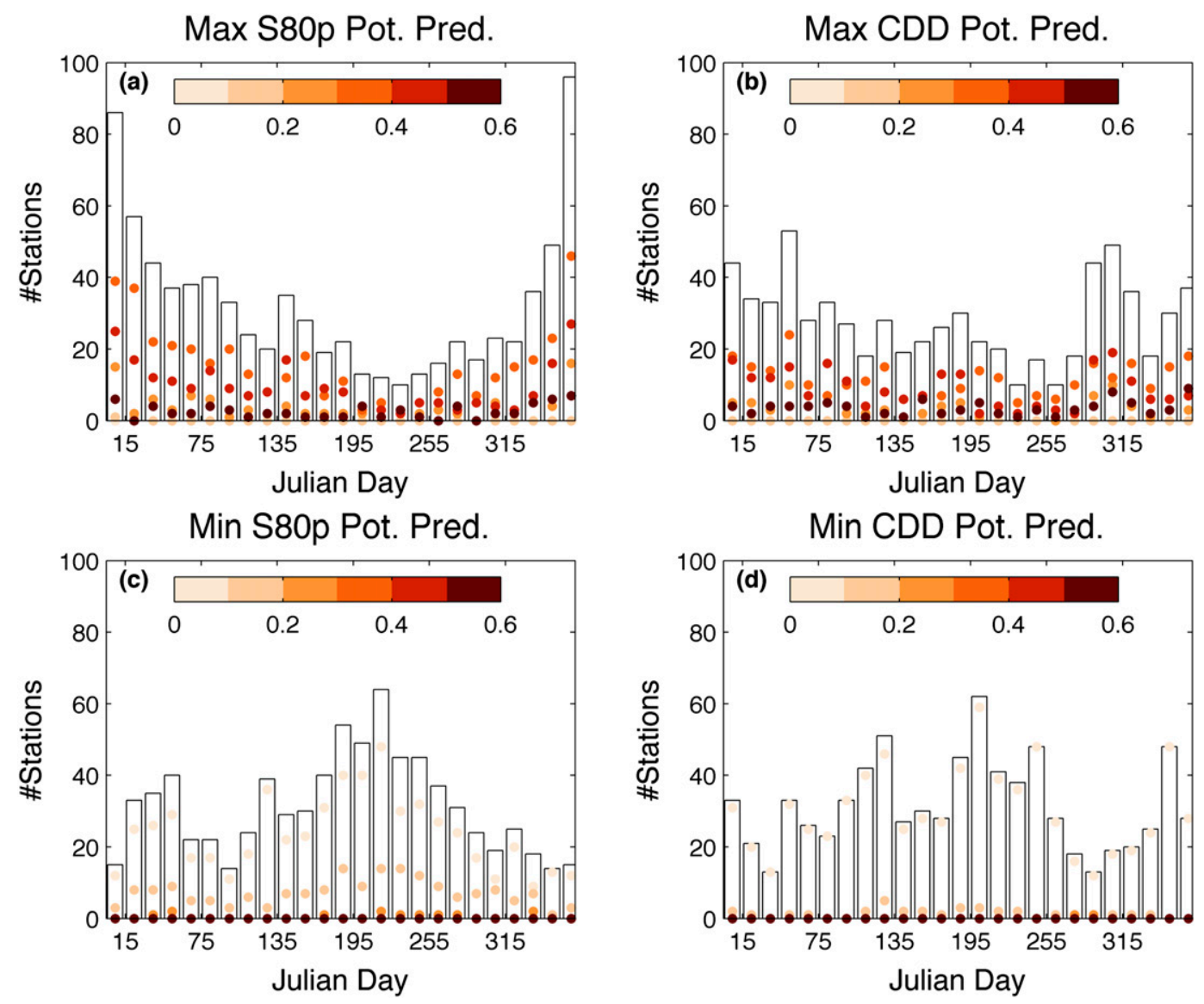

FIG. 9. (a) Bars represent the number of stations ( $y$ axis) that experience their max PP of S80p within each 15-day window over the course of the year ( $x$ axis). Circles represent the number of stations within each 15-day window that have max PPV values within the bins designated by the color bar at the top; the sum of the number of stations across all six bins is equivalent to the bar height for that 15-day window. (b) As in (a), but for number of stations that experience their max PP of longest CDD length. (c),(d) As in (a) and (b), but for the number of stations that experience their min PP of S80p and longest CDD lengths, respectively.

better characterize the changing nature of the extremes and the processes underlying these changes (e.g., Gianotti et al. 2014; Zolina et al. 2010). Given the daily station-based observations along with the SSWM data, it is possible to carry out similar potential predictability studies for a broad array of metrics for which predictions (or projections) might be made. In addition, while visually there is spatial continuity in the results across many regions, there are also regions with considerable spatial inhomogeneities. Currently, the SSWMs lack an explicit spatial component; by addressing this weakness and incorporating spatial dependence between stations within the SSWMs (e.g., Khalili et al. 2007; Kleiber et al. 2012), it may be feasible to obtain even more spatially coherent potential predictable estimates.

Nevertheless, by identifying hot-spot regions of historical predictability that may be strongly influenced by changes in the underlying precipitation-producing processes, we are effectively isolating regions in which we may have the most potential success in making climate forecasts, either using short-term seasonal forecasting systems or long-term climate simulation systems. Further, cold spots of potential predictability provide guidance on regions/seasons that are most likely to experience spurious, noise-induced extremes. As such even if a given forecast system provides "confident" forecasts of seasonal precipitation extremes in these regions, such extremes are unlikely to be manifested in the observed system because of the influence of stochastic, shortmemory meteorological processes. In turn, identification of these hot- and cold-spot regions can help constrain the robustness and reliability of forecasted seasonal precipitation extremes and guide the issuance of forecasts of these extremes (e.g., Barnston and Mason 2011). That said, it is important to note that results here indicate that, even during seasons in which a given station's PPV is at 
its maximum, only $8 \%$ and $15 \%$ of the stations have PPV values greater than 0.5 for heavy precipitation accumulations and extreme dry spell lengths, respectively; further, the median maximum PPV across all stations is 0.37 and 0.39 , respectively. These results suggest that, even during seasons with enhanced potential predictability, for most stations more than $50 \%$ of the observed variance in seasonal rainfall extremes-and for over half the stations more than $60 \%$ of the observed variance-is attributable to the stochastic, short-memory behavior of typical meteorological events over time and as such is inherently unpredictable.

Finally, the identification of hot-spot regions of historical predictability (both with regard to region and season) can engender future analyses of the physical drivers-including soil moisture, snow cover, vegetation and atmospheric teleconnections, as well as other sources of predictability - and subsequent precipitation responses to these drivers, which together give rise to the enhanced potential predictability itself. For instance, it is expected that the enhanced early to late winter predictability of heavy precipitation accumulations across the West Coast is connected to remote forcing by El Niño-Southern Oscillation (ENSO) variability (Ropelewski and Halpert 1986), while the enhanced late summer predictability of extreme dry spell lengths over the central plains is connected to local soil moisture-induced intensification/ suppression of convective activity (Findell et al. 2011). To aid in these "attribution" type efforts, we have posted the potentially predictable variance values for each station, each 91-day season (centered on all 365 Julian days), and each metric (including total seasonal accumulation) as supplemental material so as to allow others in the research, operations, and user communities to evaluate the location, timing, and utility of extreme precipitation predictions of most relevance to them.

Acknowledgments. The authors would like to give special thanks to Angela Rigden for her help with the spatial analysis. We also extend our thanks to the two anonymous reviewers for their constructive and insightful comments. This work was supported by the National Science Foundation (AGS-0958907) and Department of Energy (DE-SC0006914).

\section{REFERENCES}

Alexander, L. V., and Coauthors, 2006: Global observed changes in daily climate extremes of temperature and precipitation. J. Geophys. Res., 111, D05109, doi:10.1029/ 2005JD006290.

Barnston, A. G., and S. J. Mason, 2011: Evaluation of IRI's seasonal climate forecasts for the extreme $15 \%$ tails. Wea. Forecasting, 26, 545-554, doi:10.1175/WAF-D-10-05009.1.
Becker, E. J., H. Van den Dool, and M. Pena, 2013: Short-term climate extremes: Prediction skill and predictability. J. Climate, 26, 512-531, doi:10.1175/JCLI-D-12-00177.1.

Boer, G. J., 2000: A study of atmosphere-ocean predictability on long time scales. Climate Dyn., 16, 469-477, doi:10.1007/ s003820050340.

_ 2004: Long time-scale potential predictability in an ensemble of coupled climate models. Climate Dyn., 23, 29-44, doi:10.1007/ s00382-004-0419-8.

_ predictability of precipitation and temperature. Geophys. Res. Lett., 35, L05706, doi:10.1029/2008GL033234.

Chen, C.-T., and T. Knutson, 2008: On the verification and comparison of extreme rainfall indices from climate models. J. Climate, 21, 1605-1621, doi:10.1175/2007JCLI1494.1.

Collins, M., 2002: Climate predictability on interannual to decadal time scales: The initial value problem. Climate Dyn., 19, 671692, doi:10.1007/s00382-002-0254-8.

Doblas-Reyes, F. J., J. García-Serrano, F. Lienert, A. P. Biescas, and L. R. L. Rodrigues, 2013: Seasonal climate predictability and forecasting: Status and prospects. Wiley Interdiscip. Rev.: Climate Change, 4, 245-268, doi:10.1002/wcc.217.

Easterling, D. R., and Coauthors, 2000: Climate extremes: Observations, modeling and impacts. Science, 289, 2068-2074, doi:10.1126/science.289.5487.2068.

Feng, X., T. DelSole, and P. Houser, 2011: Bootstrap estimated seasonal potential predictability of global temperature and precipitation. Geophys. Res. Lett., 38, L07702, doi:10.1029/ 2010 GL046511.

Findell, K., P. Gentine, B. Lintner, and C. Kerr, 2011: Probability of afternoon precipitation in eastern United States and Mexico enhanced by high evaporation. Nat. Geosci., 4, 434-439, doi:10.1038/ngeo1174.

Fowler, H. J., and M. Ekström, 2009: Multi-model ensemble estimates of climate change impacts on UK seasonal precipitation extremes. Int. J. Climatol., 29, 385-416, doi:10.1002/ joc. 1827.

— cipitation extremes using regional climate model projections: Implications for managing fluvial flood risk. Water Res. Res., 46, W03525, doi:10.1029/2008WR007636.

Gianotti, D. J., B. T. Anderson, and G. D. Salvucci, 2013: What do rain gauges tell us about the limits of precipitation predictability? J. Climate, 26, 5682-5688, doi:10.1175/JCLI-D-12-00718.1.

,$- \ldots$, and,- 2014 : The potential predictability of precipitation occurrence, intensity, and seasonal totals over the continental United States. J. Climate, 27, 6904-6918, doi:10.1175/ JCLI-D-13-00695.1.

Gregory, J. M., T. M. L. Wigley, and P. D. Jones, 1993: Application of Markov models to area-average daily precipitation series and interannual variability in seasonal totals. Climate Dyn., 8, 299-310, doi:10.1007/BF00209669.

Groisman, P. Ya., and R. W. Knight, 2008: Prolonged dry episodes over the conterminous United States: New tendencies emerging during the last 40 years. J. Climate, 21, 1850-1862, doi:10.1175/2007JCLI2013.1.

— itation over the central United States. J. Hydrometeor., 13, 4766, doi:10.1175/JHM-D-11-039.1.

Hamlet, A. F., and D. P. Lettenmaier, 2005: Production of temporally consistent gridded precipitation and temperature fields for the continental United States. J. Hydrometeor., 6, 330-336, doi:10.1175/JHM420.1. 
Hurvich, C. M., and C.-L. Tsai, 1989: Regression and time series model selection in small samples. Biometrika, 76, 297-307, doi:10.1093/biomet/76.2.297.

Hutchinson, M. F., 1995: Interpolating mean rainfall using thin plate smoothing splines. Int. J. Geogr. Inf. Syst., 9, 385-403, doi:10.1080/02693799508902045.

— 2007: ANUSPLIN version 4.4 user guide. Centre for Resource and Environmental Studies, Australian National University, Canberra, NSW, Australia, 52 pp. [Available online at http://fennerschool.anu.edu.au/files/anusplin44.pdf.]

Katz, R. W., 1977: Precipitation as a chain-dependent process. J. Appl. Meteor., 16, 671-676, doi:10.1175/1520-0450(1977)016<0671: PAACDP $>2.0 . C O ; 2$.

—_, and M. B. Parlange, 1998: Overdispersion phenomenon in stochastic modeling of precipitation. J. Climate, 11, 591-601, doi:10.1175/1520-0442(1998)011<0591:OPISMO>2.0.CO;2.

Khalili, M., R. Leconte, and F. Brissette, 2007: Stochastic multisite generation of daily precipitation data using spatial autocorrelation. J. Hydrometeor., 8, 396-412, doi:10.1175/ JHM588.1.

Kiktev, D., J. Caesar, L. V. Alexander, H. Shiogama, and M. Collier, 2007: Comparison of observed and multimodeled trends in annual extremes of temperature and precipitation. J. Geophys. Res., 34, L10702, doi:10.1029/2007GL029539.

Kleiber, W., R. Katz, and B. Rajagopalan, 2012: Daily spatiotempora precipitation simulation using latent and transformed Gaussian processes. Water Resour. Res., 48, W01523, doi:10.1029/ 2011WR011105.

Klein Tank, A. M. G., F. W. Zwiers, and X. Zhang, 2009: Guidelines on analysis of extremes in a changing climate in support of informed decisions for adaptation. WCDMP-72, WMO-TD 1500 $56 \mathrm{pp}$. [Available online at www.wmo.int/datastat/documents/ WCDMP_72_TD_1500_en_1_1.pdf.]

Kogan, F. N., 1995: Droughts of the late 1980s in the United States as derived from NOAA polar-orbiting satellite data. Bull. Amer. Meteor. Soc., 76, 655-668, doi:10.1175/1520-0477(1995)076<0655: DOTLIT $>2.0 . \mathrm{CO} ; 2$

Kumar, A., M. Chen, M. Hoerling, and J. Eischeid, 2013: Do extreme climate events require extreme forcings? Geophys. Res. Lett., 40, 3440-3445, doi:10.1002/grl.50657.

— , P. Pen, and M. Chen, 2014: Is there a relationship between potential and actual skill? Mon. Wea. Rev., 142, 2220-2227, doi:10.1175/MWR-D-13-00287.1.

Leander, R., R. A. Buishand, and A. M. G. Klein Tank, 2014: An alternative index for the contribution of precipitation on very wet days to the total precipitation. J. Climate, 27, 1365-1378, doi:10.1175/JCLI-D-13-00144.1.

Leith, C., 1978: Predictability of climate. Nature, 276 (Suppl.), 352355, doi:10.1038/276352a0.

Madden, R. A., 1976: Estimates of the natural variability of time averaged sea level pressure. Mon. Wea. Rev., 104, 942-952, doi:10.1175/1520-0493(1976)104<0942:EOTNVO>2.0.CO;2.

—_, and D. J. Shea, 1978: Estimates of the natural variability of time-averaged temperatures over the United States. Mon. Wea. Rev., 106, 1695-1703, doi:10.1175 1520-0493(1978)106<1695:EOTNVO > 2.0.CO;2.

May, W., 2004: Variability and extremes of daily rainfall during the Indian summer monsoon in the period 1901-1989. Global Planet. Change, 44, 83-105, doi:10.1016/j.gloplacha.2004.06.007.

Moron, V., A. W. Robertson, and M. N. Ward, 2006: Seasonal predictability and spatial coherence of rainfall characteristics in the tropical setting of Senegal. Mon. Wea. Rev., 134, 32483260, doi:10.1175/MWR3252.1.
Pal, I., B. T. Anderson, G. D. Salvucci, and D. Gianotti, 2013: Shifting seasonality and increasing frequency of precipitation in wet and dry seasons across the U.S. Geophys. Res. Lett., 40 , 4030-4035, doi:10.1002/grl.50760.

Peterson, T. C., C. Folland, G. Gruza, W. Hogg, A. Mokssit, and N. Plummer, 2001: Report on the activities of the working group on climate change detection and related rapporteurs 1998-2001. WCDMP-47, WMO-TD 1071, 143 pp.

Phillips, D., 2002: The top ten Canadian Weather Stories for 2001. CMOS Bulletin, Vol. 30, Canadian Meteorological and Oceanographic Society, Ottawa, ON, Canada, 19-23.

Pryor, S. C., J. A. Howe, and K. E. Kunkel, 2009: How spatially coherent and statistically robust are temporal changes in extreme precipitation in the contiguous USA? Int. J. Climatol., 29, 31-45, doi:10.1002/joc.1696.

Reek, T., S. R. Doty, and T. W. Owen, 1992: A deterministic approach to the validation of historical daily temperature and precipitation data from the cooperative network. Bull. Amer. Meteor. Soc., 73, 753-762, doi:10.1175/1520-0477(1992)073<0753: ADATTV $>2.0 . \mathrm{CO} ; 2$

Riebsame, W. E., S. A. Changnon, and T. R. Karl, 1990: Drought and Natural Resource Management in the United States: Impacts and Implications of the 1987-1989 Drought. Westview Press, $174 \mathrm{pp}$

Robertson, A. W., V. Moron, and Y. Swarinoto, 2009: Seasonal predictability of daily rainfall statistics over Indramayu district, Indonesia. Int. J. Climatol., 29, 1449-1462, doi:10.1002/ joc.1816.

Ropelewski, C. F., and M. S. Halpert, 1986: North American precipitation and temperature patterns associated with the El Niño/Southern Oscillation (ENSO). Mon. Wea. Rev., 114, 2352-2362, doi:10.1175/1520-0493(1986)114<2352: NAPATP $>2.0 . C O ; 2$.

Rowell, D. P., 1998: Assessing potential seasonal predictability with an ensemble of multidecadal GCM simulations. J. Climate, 11, 109-120, doi:10.1175/1520-0442(1998)011<0109: APSPWA $>2.0 . \mathrm{CO} ; 2$.

Schubert, S. D., M. J. Suarez, P. J. Pegion, R. D. Koster, and J. T. Bacmeister, 2008: Potential predictability of long-term drought and pluvial conditions in the U.S. Great Plains. J. Climate, 21, 802-816, doi:10.1175/2007JCLI1741.1.

Shea, D. J., and R. A. Madden, 1990: Potential for long-range prediction of monthly mean surface temperatures over North American. J. Climate, 3, 1444-1451, doi:10.1175/1520-0442(1990)003<1444: PFLRPO $>2.0 . \mathrm{CO} ; 2$.

Singh, S. W., and R. H. Kripalani, 1986: Potential predictability of lowertropospheric monsoon circulation and rainfall over India. Mon. Wea. Rev., 114, 758-763, doi:10.1175/1520-0493(1986)114<0758: PPOLTM $>2.0 . \mathrm{CO} ; 2$.

Stocker, T., C. Field, Q. Dahe, V. Barros, G.-K. Plattner, M. Tignor, P. Midgley, and K. Ebi, Eds., 2010: IPCC expert meeting on detection and attribution related to anthropogenic climate change. Meeting Rep., IPCC/WMO, Geneva, Switzerland, 55 pp. [Available online at www.ipcc.ch/pdf/supporting-material/ expert-meeting-detection-anthropogenic-2009-09.pdf.]

Swift, L. W., and H. T. Schreuder, 1981: Fitting daily precipitation amounts using the $\mathrm{S}_{\mathrm{B}}$ distribution. Mon. Wea. Rev., 109, 2535-2540, doi:10.1175/1520-0493(1981)109<2535:FDPAUT>2.0.CO;2.

Tebaldi, C., K. Hayhoe, J. M. Arblaster, and G. A. Meehl, 2006: Going to the extremes. Climatic Change, 79, 185-211, doi:10.1007/ s10584-006-9051-4.

Verbist, K., A. W. Robertson, W. M. Cornelis, and D. Gabriels, 2010: Seasonal predictability of daily rainfall characteristics in 
central-northern Chile for dry-land management. J. Appl. Meteor. Climatol., 49,1938-1955, doi:10.1175/2010JAMC2372.1.

Wang, J., B. T. Anderson, and G. Salvucci, 2006: Stochastic modeling of daily summertime rainfall over the southwestern United States. Part I: Interannual variability. J. Hydrometeor., 7, 739-754, doi:10.1175/JHM518.1.

— — - and _ 2007: Stochastic modeling of daily summertime rainfall over the southwestern United States. Part II: Intraseasonal variability. J. Hydrometeor., 8, 938-951, doi:10.1175/JHM592.1.

Wilks, D. S., 1999: Interannual variability and extreme-value characteristics of several stochastic daily precipitation models. Agric. For. Meteor., 93, 153-169, doi:10.1016/ S0168-1923(98)00125-7.

Williams, C. N., R. S. Vose, D. R. Easterling, and M. J. Menne, 2006: United States historical climatology network daily temperature, precipitation, and snow data. Carbon Dioxide Information Analysis Center, Oak Ridge National Laboratory, Oak Ridge, TN. [Available online at http://cdiac.esd.ornl.gov/epubs/ndp/ ushon/ushon.html.]

Wu, W., and Coauthors, 2012: Statistical downscaling of climate forecast system seasonal predictions for the southeastern Mediterranean. Atmos. Res., 118, 346-356, doi:10.1016/ j.atmosres.2012.07.019.
Zhang, X., F. W. Zwiers, and G. Li, 2004: Monte Carlo experiments on the detection of trends in extreme values. J. Climate, 17, 1945-1952, doi:10.1175/1520-0442(2004)017<1945: MCEOTD $>2.0 . C O ; 2$.

— L. Alexander, G. C. Hegerl, P. Jones, A. Klein Tank, T. C. Peterson, B. Trewin, and F. W. Zwiers, 2011: Indices for monitoring changes in extremes based on daily temperature and precipitation data. Wiley Interdiscip. Rev.: Climate Change, 2, 851-870, doi:10.1002/wcc.147.

Zheng, X., H. Nakamura, and J. A. Renwick, 2000: Potential predictability of seasonal means based on monthly time series of meteorological variables. J. Climate, 13, 2591-2604, doi:10.1175/1520-0442(2000)013<2591:PPOSMB > 2.0.CO;2.

Zolina, O., C. Simmer, K. Belyaev, A. Kapala, and S. Gulev, 2009: Improving estimates of heavy and extreme precipitation using daily records from European rain gauges. J. Hydrometeor., 10, 701-716, doi:10.1175/2008JHM1055.1.

,-- , S. K. Gulev, and S. Kollet, 2010: Changing structure of European precipitation: Longer wet periods leading to more abundant rainfalls. Geophys. Res. Lett., 37, L06704, doi:10.1029/ 2010GL042468.

, K. Belyaev, S. K. Gulev, and P. Koltermann, 2013: Changes in the duration of European wet and dry spells during the last 60 years. J. Climate, 26, 2022-2047, doi:10.1175/JCLI-D-11-00498.1. 